\title{
A Covid-19 e seus efeitos na renda dos músicos brasileiros
}

\author{
Clara Sandroni | Universidade Federal de Minas Gerais | Brasil \\ Daniela Maria Ferreira | Universidade Federal de Pernambuco | Brasil \\ Luciana Pires de Sá Requião | Universidade Federal Fluminense | Brasil \\ Carlos Sandroni | Universidade Federal de Pernambuco | Brasil \\ Margareth Guimarães Lima | Universidade Estadual de Campinas | Brasil
}

\begin{abstract}
Resumo: Este artigo apresenta os resultados parciais de uma pesquisa sobre o trabalho do músico durante a pandemia da Covid-19. A partir de uma análise de regressão logística simples e múltipla, realizada com dados coletados por meio de um questionário virtual (RedCap), identificou-se e comparou-se as características demográficas e socioeconômicas de musicistas residentes nas grandes regióes do Brasil. Isso permitiu examinar a relação entre a perda de renda e as características demográficas, socioeconômicas, escolares e empregatícias dos músicos. Os resultados revelam que os musicistas que mais perderam renda estão entre aqueles autodeclarados negros, com menor escolarização (anos de estudos), mais jovens e que não tinham vínculo trabalhista formal antes da pandemia. São também os musicistas do sexo masculino, em sua maioria os principais provedores, que mais perderam renda quando comparada com as mulheres da amostra, que por sua vez, são as mais escolarizadas.
\end{abstract}

Palavras-chave: Covid-19, Renda, Musicistas, Brasil

\begin{abstract}
This article presents partial results of a research on the musicians' job market during the Covid-19 pandemic. The research was based on a simple and multiple regression analysis and performed with data collected through an online questionnaire (RedCap). It was possible to identify and compare demographic and socioeconomic features of musicians from the larger regions of Brazil. This method allowed us to examine the relationship between loss of income and musicians' demographic, socioeconomic, academic level, and employment features. Results show that musicians who faced the greatest income reduction were among the self-identified as blacks, those with lower academic level (less years of study), the younger ones who did not have formal employment before the pandemic. Male musicians, who are largely the main family providers, are also among those who experienced more income loss when compared with the female share of the sample, who, in turn, have higher academic level.
\end{abstract}

Keywords: Covid-19, Income, Musician, Brazil. 

autoridades sanitárias reconheceram como sendo derivado de um novo tipo de Coronavírus, chamado de Coronavírus 19, resultando na doença da Covid-19¹ . Com a disseminação do vírus para outros países, no dia 11 de março de 2020 a OMS decretou a existência de uma pandemia. No dia 25 de fevereiro, em São Paulo, foi detectado o primeiro caso da Covid-19 no Brasil, alóctone, oriundo da Itália. Logo as populaçôes das grandes capitais, dentre outras cidades, foram aderindo ao isolamento social e os locais onde ocorre aglomeração de pessoas foram fechados, incluindo lugares de shows de grande e pequeno porte, os bares, os estúdios de gravação de grandes e pequenas empresas, as escolas, as feiras e festivais culturais, enfim todos os locais onde musicistas estavam trabalhando ou poderiam trabalhar.

Muito tem se falado sobre o impacto do isolamento social provocado pela pandemia da Covid-19 na classe artística. Os noticiários mostram diariamente as dificuldades enfrentadas pelos artistas que, assim como trabalhadores de outros setores econômicos (comerciantes, feirantes, serviços educacionais, de transporte, de beleza, de moda, turismo, entretenimento, entre outros) estão impossibilitados de realizar suas atividades. No caso específico dos músicos, além dos shows, eventos e concertos presenciais (única fonte de renda para parte do segmento), o trabalho realizado em estúdios de gravação, para realização de produções audiovisuais, como trilhas sonoras para emissoras de TV, rádio e streaming também foram suspensos. Vários são os relatos de músicos apontando os prejuízos financeiros, sociais e emocionais decorrentes do cancelamento das agendas de apresentações e gravações previstas para o ano de $2020^{2}$.

\footnotetext{
1 "OMS Declara Pandemia de Coronavírus: o que isso significa?" Sociedade Brasileira de Medicina de Família e Comunidade. Disponível em: https://www.sbmfc.org.br/noticias/oms-declara-pandemia-de-coronavirus-o-que-issosignifica/ Acesso em: 20 jan. 2021.

2 "Conexão Cultural ajuda a reduzir dificuldades enfrentadas por artistas maranhenses durante pandemia" Maranhão de Todos Nós. Disponível em: https://www.ma.gov.br/agenciadenoticias/?p=277207 Acesso em: 20 jan. 2021. "Músicos relatam como a pandemia está afetando projetos". Jornal Bom Dia. Disponível em: https://www.jornalbomdia.com.br/noticia/38973/musicos-relatam-como-a-pandemia-esta-afetando-projetos Acesso em: 20 jan. 2021.

"Artistas locais se reinventam para driblar a crise trazida pela pandemia". Correio Brasiliense. Disponível em: https://www.correiobraziliense.com.br/app/noticia/diversao-earte/2020/03/24/interna_diversao_arte,836155/artistas-locais-se-reinventam-para-driblar-a-crise-trazida-pelapandem.shtml Acesso em: 20 jan. 2021.

"Campanha vai socorrer artistas patenses que ficaram sem trabalho por causa da pandemia”. Patos Hoje. Disponível em: https://www.patoshoje.com.br/noticias/campanha-vai-socorrer-artistas-patenses-que-ficaram-sem-trabalho-porcausa-da-pandemia-61562.html Acesso em: 20 jan. 2021.
} 
Distantes dos palcos, estúdios, bares, clubes e festas, os musicistas têm desenvolvido diferentes atividades para diminuir a perda financeira e garantir o básico e o mínimo de conforto aos seus familiares, e também para recuperar o ânimo com o trabalho em meio ao acirramento da instabilidade comum ao setor, agravada pela nova realidade. Enquanto alguns contam, literalmente, com a ajuda de familiares, amigos e associações culturais para enfrentar a situação atual, outros têm promovido rifas, bingos, "vaquinhas" virtuais, realizado vendas de instrumentos musicais e discos, entrega de alimentos por aplicativos e produzido lives (shows online), além de cursos/aulas virtuais.

A área cultural brasileira já vinha sofrendo perdas econômicas e políticas significativas desde antes da pandemia da Covid-19. Criado em 1985, no governo de José Sarney³, o Ministério da Cultura foi extinto pelo governo interino de Michel Temer (2016-2018) e reincorporado ao Ministério da Educação, mas, depois de intensos protestos da classe artística, a decisão foi revertida e o MinC foi "recriado" agora com direção de Roberto Freire ${ }^{4}$. No período do governo Temer a cultura perdeu $43 \%$ de sua verba 5 . Já a partir de 2019, no governo do presidente Jair Bolsonaro, o Ministério da Cultura é extinto, mais uma vez, transformado em uma secretaria atrelada ao recémcriado Ministério da Cidadania, porém, em sete de novembro de 2019 a pasta especial da Cultura é

\footnotetext{
"Músicos de Salvador devem receber cestas básicas a partir da próxima quinta-feira (14)” Jornal Cinco Disponível em: https://jornalcinco.com.br/2020/05/musicos-salvador-cestas-basicas/ Acesso em: 20 jan. 2021.

"Artistas recebem cestas básicas doadas nas lives do projeto Showlidariedade in Serrinha" Portal Ferraz e o Povo Disponível em: https://www.joseferraz.com.br/2020/06/artistas-recebem-cestas-basicasdoadas.html\#: :text=Artistas\%20recebem\%20cestas\%20b\%C3\%A1sicas\%20doadas\%20nas\%20lives\%20do,voltado\%20 para\%20arrecada\%C3\%A7\%C3\%A3o\%20de\%20alimentos\%20e\%20doa\%C3\%A7\%C3\%B5es\%20 Acesso em: 20 jan. 2021.

"Profissionais do segmento de eventos recebem cestas básicas" Nossa Metrópole Disponível em: https://nossametropole.com.br/2020/06/03/profissionais-do-segmento-de-eventos-recebem-cestas-basicas/ Acesso em: 20 jan. 2021.

"De lives a venda de salgados: músicos contam como se mantêm durante a pandemia" Cultura IG Disponível em: https://gente.ig.com.br/cultura/2020-07-13/de-lives-a-venda-de-salgados-musicos-contam-como-se-mantem-durantea-pandemia.html Acesso em: 20 jan. 2021.

${ }^{3}$ Conforme disponível em: <http://portalsnc.cultura.gov.br/historico-2/> Acesso em 4 out. 2020.

4 "Temer decide recriar Ministério da Cultura; ministro assume na terça" G1 Disponível em: http://g1.globo.com/politica/noticia/2016/05/temer-decide-recriar-ministerio-da-cultura-anuncio-deve-ser-naterca.html Acesso em 4 out. 2020.

5 "Entenda o vaivém da cultura no governo Bolsonaro e quais os planos para as políticas públicas na área" GZH Disponível em: https://gauchazh.clicrbs.com.br/cultura-e-lazer/noticia/2019/11/entenda-o-vaivem-da-cultura-nogoverno-bolsonaro-e-quais-os-planos-para-as-politicas-publicas-na-area-ck $307 \mathrm{~m} 1 \mathrm{yn} 00 \mathrm{~g} 801 \mathrm{mq} 3 \mathrm{dmek} 1 \mathrm{rs}$.html Acesso em 4 out. 2020.
} 
transferida mais uma vez, agora para a pasta do Turismo ${ }^{6}$. Com toda essa instabilidade e desamparo, a área da cultura também não estava preparada para passar pela crise que viria com a pandemia.

Na tentativa de mitigar a perda econômica para a classe artística no país, em junho de 2020, o Congresso Nacional sancionou a Lei Aldir Blanc ${ }^{7}$, que oferece auxílio financeiro para o setor cultural. De acordo com a lei, serão liberados três bilhões de reais para estados e municípios no intuito de apoiar espaços culturais, trabalhadores diretos e outras iniciativas a exemplo de editais e chamadas públicas direcionadas ao campo artístico. Este auxílio emergencial direto ao trabalhador da área cultural veio em três parcelas de 600 reais, a partir do mês de setembro do mesmo ano. Embora seja um valor de contribuição que está acima da renda familiar dos indivíduos economicamente mais frágeis e é maior do que a recebida pelo Programa Bolsa Família (BARBOSA E PRATES, 2020, p. 2-3), pode não ser suficiente para solucionar problemas que a perda da renda durante a pandemia poderia ocasionar.

Com intuito de desenvolver uma reflexão sobre os efeitos do distanciamento social devido à pandemia da Covid-19 na renda de musicistas brasileiros, realizamos este estudo com o objetivo de identificar as variáveis sociais que mais se associam à perda financeira dos músicos nos últimos meses. Desta maneira, a pesquisa pode traçar um perfil com as características sociodemográficas e socioeconômicas dos indivíduos que mais perderam renda durante a pandemia da Covid-19, bem como identificar os grupos mais vulneráveis ao prejuízo nos proventos mensais com a música, no período estudado.

\section{Metodologia}

A análise apresentada no presente artigo deriva do projeto de pesquisa intitulado "EPIMúsica: o trabalho do músico durante a pandemia de Covid-19”. O EPI-Música é um estudo transversal conduzido para avaliar o impacto das medidas de distanciamento social nas práticas

\footnotetext{
6 "Entenda o vaivém da cultura no governo Bolsonaro e quais os planos para as políticas públicas na área" GZH Disponível em: https://gauchazh.clicrbs.com.br/cultura-e-lazer/noticia/2019/11/entenda-o-vaivem-da-cultura-nogoverno-bolsonaro-e-quais-os-planos-para-as-politicas-publicas-na-area-ck $307 \mathrm{~m} 1 \mathrm{yn} 00 \mathrm{~g} 801 \mathrm{mq} 3 \mathrm{dmek} 1 \mathrm{rs}$.html Acesso em 4 out. 2020.

${ }^{7}$ Lei № 14.017, de 29 de junho de 2020 Disponível em: https://www.in.gov.br/en/web/dou/-/lei-n-14.017-de-29-dejunho-de-2020-264166628 Acesso em 4 out. 2020.
} 
musicais, nos rendimentos, no trabalho e na saúde emocional de músicos residentes nas cinco grandes regióes brasileiras. $\mathrm{O}$ arcabouço teórico-metodológico que orienta a discussão dos nossos dados advém das pesquisas que tratam das condiçôes e relaçôes de trabalho dos músicos, em especial, aquelas que procuram compreender as reconfigurações dos percursos e carreiras dos musicistas nas últimas décadas, em função da flexibilidade, informalidade e precariedade provocada pela reestruturação produtiva e a acumulação flexível, ocorrida nos últimos 40 anos (COSTA, 2020; REQUIÃO, 2010, 2016, 2017, 2019, 2020a e 2020b; SEGNINI, 2011; MENGER, 2005). Além dessa literatura, nosso estudo também mobilizou as reflexões acumuladas pelas pesquisas sociológicas dedicadas a entender as relações entre investimento escolar e mobilidade social. Tais pesquisas mostram como, paralelamente ao desenvolvimento das novas modalidades de trabalho (formais, não formais, temporárias, etc.), que atingem diversas atividades econômicas, o prolongamento dos estudos ainda se constitui numa estratégia importante no processo de reprodução de diferentes estratos sociais, mas também de defesa diante das incertezas econômicas e de prejuízos profissionais (PEUGNY, 2014; POCHMANN, 2012; RIBEIRO, 2011; VARGAS, 2009; HASENBALG E VALLE SILVA, 2003; BAUDELOT, 2004; SEGNINI, 2000). Essa perspectiva analítica nos conduziu, de um lado, a pensar a situação financeira dos músicos durante a pandemia da Covid-19, não apenas em função das características sociais e demográficas, mas também das condições de trabalho anteriores ao isolamento social e do grau de escolarização.

O percurso metodológico trilhado para pensar a situação dos musicistas utilizou um questionário virtual. Este instrumento de pesquisa foi elaborado com utilização do aplicativo RedCap (Research Electronic Data Capture), uma plataforma online de coleta e gerenciamento de dados. As informaçôes foram armazenadas no servidor da Faculdade de Ciências Médicas da Universidade Estadual de Campinas (FCM/UNICAMP). O questionário contou com a maior parte das questôes fechadas, sobre informações demográficas, socioeconômicas, culturais, tipo de ocupação e possíveis alterações, e questôes sobre saúde emocional dos entrevistados durante a pandemia da Covid-19. Os dados foram coletados via web (por internet) no período de 03/07/2020 a 25/07/2020. Neste trabalho utilizamos apenas as respostas às questóes que se relacionavam aos objetivos do estudo.

Para obter um tamanho de amostra mínimo para a realização de estimativas de médias e 
percentuais seria necessário um número de 390 respondentes, considerando uma proporção de 0,50, referente à máxima variabilidade da amostra, intervalo de confiança de $95 \%(\mathrm{z}=1,96)$ e erro amostral de 5 pontos percentuais. Foram entrevistadas 516 pessoas de ambos os sexos. A questão da assinatura do Termo de Consentimento Livre e Esclarecido (TCLE) não foi respondida por 32 pessoas e 8 indivíduos submeteram o questionário sem respostas, somando uma perda de 7,8\%, totalizando 476 respondentes. Dentre estes, alguns deixaram de responder alguma questão do questionário e foram tratados como missing (dados faltantes).

A amostra foi recrutada por meio de amostragem por "bola de neve". Os pesquisadores do estudo disseminaram o questionário para, pelo menos, 20 músicos de suas redes ${ }^{8}$. Para estes foi pedido que enviassem para mais 4 músicos. Estas 20 pessoas contatadas pelos pesquisadores foram recrutadas de forma sistemática garantindo a participação de músicos em várias faixas de idade (18 a 39 anos, 40 a 59 e 60 ou mais) e vivendo nas cinco grandes regióes do país: Norte, Nordeste, Sul, Sudeste e Centro-Oeste. Também foi solicitado que sindicatos e associações de músicos fizessem uma divulgação via e-mail para seus contatos.

Foram consideradas elegíveis para responder o questionário quaisquer pessoas que se considerassem músicos, com 18 anos ou mais, residentes no território brasileiro durante a pandemia. Pessoas sem acesso à internet para responder o questionário foram excluídas do processo amostral.

Foi feito um upload (envio para a plataforma digital) do Termo de Consentimento Livre e Esclarecido (TCLE) para o RedCap a fim de disponibilizá-lo para acesso e leitura do respondente antes de responder o questionário. A pessoa também poderia fazer download (acessar o documento) do TCLE e salvá-lo em seu computador ou celular. A assinatura do respondente foi substituída pela ação de clicar em "Sim” para concordar em responder a pesquisa, após ter lido o TCLE, antes de responder o questionário. Se o respondente clicasse em "Não", o navegador seria fechado ou não submeteria as informações. O projeto foi aprovado pelo Comitê de Ética em Pesquisa (CEP) da Faculdade de Ciências Médicas (FCM) da UNICAMP, sob parecer no 4.110.118, CAAE no 33160120.8 .0000 .5404 .

\footnotetext{
${ }^{8}$ O grupo de pesquisa da EPI-Música é formado por pesquisadores da UNICAMP, da Universidade Federal de Minas Gerais (UFMG), Universidade Federal de Pernambuco (UFPE) e da Universidade Federal Fluminense (UFF), das áreas da música e da epidemiologia.
} 
As variáveis utilizadas neste estudo compreenderam o sexo, faixa etária (“18 a 39 anos”, “40 a 49 anos”, "50 e mais”), cor da pele ("brancos”, "pretos” e "pardos”, conforme utilização proposta pelo Instituto Brasileiro de Geografia e Estatística; para a parte analítica do estudo as categorias “preta” e "parda" foram unidas e compuseram a categoria "negros”), regióes brasileiras ("Norte”, "Nordeste”, "Sul”, "Sudeste” e "Centro-Oeste”), renda per capita em salários mínimos (SM) ("até 1 SM", “1 a 2", "2 a 4" e “4 ou mais”), renda além dos proventos com a música ("não", "sim”), quanto a música representa no salário (“menos que $80 \%$ ", “80\% ou mais”), provedor principal da renda do domicílio (“não", "sim”), escolaridade do entrevistado ("médio incompleto", "superior incompleto", "superior completo" e "pós-graduação" - para a parte analítica do estudo as duas primeiras categorias foram unidas), vínculo trabalhista (“formal”, “sem vínculo ou microempreendedor ou autônomo sazonal”, “empresário ou autônomo fixo”, “outros”) e pagamento de algum tipo de previdência ("não", “sim”). O evento principal, ou desfecho do estudo foi a alteração da renda individual comparando antes e depois da pandemia ("manteve ou aumentou”, “diminuiu ou perdeu renda”).

Foram estimados os percentuais de todas as variáveis do estudo segundo sexo e perda da renda e verificadas as diferenças por meio de teste de qui-quadrado de Pearson. Também estimamos os Odds Ratios (OR) brutos e ajustados por meio de regressão logística simples e múltipla. Odds Ratio é traduzido como "razão de chances" e permite verificar quanto a chance de o evento principal acontecer é maior em determinado grupo de indivíduos, em relação a outro. A regressão logística múltipla foi realizada, primeiramente, com todas as variáveis demográficas e socioeconômicas em relação à perda da renda, permanecendo no modelo aquelas com valores de $\mathrm{p}<0,05$. A associação com valores de p abaixo deste é considerada significante estatisticamente, indicando que a diferença entre os grupos não foi devida ao acaso. $\mathrm{Na}$ análise de regressão com as variáveis de rendimentos e trabalho em relação à perda da renda foram acrescentadas as variáveis que permaneceram no primeiro modelo, para ajustes dos fatores que possam confundir as associações. As análises foram conduzidas com o software estatístico STATA 15.0. 


\section{Apresentação e Discussão dos Resultados}

\subsection{Características demográficas e socioeconômicas}

Antes de passarmos para a análise da associação entre os condicionantes sociais e a perda de renda com música, é preciso caracterizar a população analisada na presente pesquisa. Foram estudadas 476 pessoas com idade média de 42,9 anos (IC95\%:41,8-44,0). Pela Tabela 1 vemos que nosso universo é composto, majoritariamente, por musicistas do sexo masculino e que se autodeclararam brancos. Enquanto as mulheres totalizaram 33,2\% da amostra, os homens representaram $66,8 \%$. A maior parte das pessoas $(67,3 \%)$ se declarou branca, e menos da metade se declarou negra $($ parda $=22,2 \%$ e preta $=10,5 \%)$.

TABELA 1 - Características demográficas da amostra segundo sexo. EPI-Música

\begin{tabular}{lccccc}
\hline Variáveis & \multicolumn{2}{c}{ Total } & $\begin{array}{c}\text { Masculino } \\
(318)\end{array}$ & $\begin{array}{c}\text { Feminino } \\
(158)\end{array}$ & $\mathrm{p}^{*}$ \\
\cline { 2 - 6 } & $\mathrm{N}$ & $\%$ & $\%$ & $\%$ & \\
\hline Total & 476 & & 66,8 & 33,2 & \\
Faixa etária & & & & & 0,506 \\
18 a 39 anos & 186 & 41,2 & 41,5 & 40,8 & \\
40 a 49 anos & 125 & 27,7 & 29,1 & 25,0 & \\
50 anos ou mais & 140 & 31,0 & 29,4 & 34,2 & \\
Cor da pele & & & & & 0,344 \\
Branca & 301 & 67,3 & 68,0 & 66,0 & \\
Preta & 47 & 10,5 & 11,6 & 8,5 & \\
Parda & 99 & 22,2 & 20,4 & 25,5 & \\
Regiónes & & & & & \\
Norte & 28 & 5,9 & 6,3 & 5,030 \\
Nordeste & 107 & 22,5 & 25,5 & 16,5 & \\
Centro-oeste & 34 & 7,1 & 8,5 & 4,4 & \\
Sudeste & 241 & 50,6 & 45,9 & 60,1 & \\
Sul & 66 & 13,9 & 13,8 & 13,9 & \\
\hline
\end{tabular}

*Valores de p, resultados do teste de qui-quadrado. São estatisticamente significantes quando apresentam valores menores do que 0,05

Esses resultados não diferem dos encontrados por pesquisas desenvolvidas sobre os músicos brasileiros e apontam que, mesmo ocorrendo um aumento da participação de mulheres e da população negra no campo da música, nas últimas décadas, esse espaço artístico continua sendo 
formado majoritariamente por homens brancos (SEGNINI, 2014, p. 75; REQUIÃO, 2020b, p. 242).

No que diz respeito à distribuição dos musicistas entre as regiôes do país (Tabela 2), nesta amostra, a maior parte vive na região Sudeste (50,6\%), no Nordeste encontram-se 22,5\%, no Sul estão 13,9\% e 13\% nas regióes Norte e Centro-oeste (Tabela 1). Segundo dados da Federação das Indústrias do Estado do Rio de Janeiro (FIRJAN, 2019), a música está dentre as profissóes mais numerosas na área da cultura no Brasil, sendo o músico intérprete instrumentista aquele que aparece em 4o lugar nesse ranking. Apesar da participação do PIB Criativo no PIB brasileiro, estimado em 2,09\% no ano 2004 e 2,61\% no ano de 2017 (FIRJAN, 2019, p. 10), e do papel de destaque do músico no desenvolvimento da área da cultura, é perceptível a paulatina redução da renda desse profissional associada ao trabalho com música. Tendo como parâmetro o estado do Rio de Janeiro, que tem alta concentração de equipamentos culturais se comparado aos demais estados, além de também concentrar, ao lado de São Paulo, o maior número e os mais bem remunerados trabalhadores desse setor produtivo (FIRJAN, 2019, p. 25), constata-se que entre 2000 e 2015 houve uma significativa perda de renda do músico no que se refere a seus ganhos especificamente musicais (lembrando que muitos músicos complementam a renda com outras atividades) (REQUIÃO, 2020a, p. 4).

Nosso estudo mostra que $21 \%$ da população analisada vive com menos de $1 \mathrm{SM}$ mensal (Tabela 2), situação declarada antes da pandemia. A pesquisa também mostra que 68,2\% da amostra declarou perder renda com a música (Tabela 3). A renda resultante do trabalho com música é proporcionalmente maior nas mulheres em relação aos homens. Contudo, são os homens, em maior parte, os principais provedores da renda do domicílio. $\mathrm{Na}$ amostra analisada, 6,9\% dos homens têm ensino médio incompleto ou menor grau, enquanto apenas $1,9 \%$ das mulheres estão neste nível de escolaridade (Tabela 2). O maior percentual de pessoas com pós-graduação lato ou stricto sensu está entre as mulheres, tendência apontada pelos estudos dedicados a compreender as disparidades educacionais entre homens e mulheres no Brasil (SOUZA, 2008, p. 175-180; OLINTO, 2012, p. 69-70; INEP, 2015, p. 23-24). Essa tendência também é confirmada pela pesquisa desenvolvida pelo núcleo de pesquisa e organização de dados e informaçôes sobre o mercado musical da Semana Internacional de Música (SIM) intitulada "Mulheres na Indústria da 
Música no Brasil: obstáculos, oportunidades e perspectivas” ao indicar que o "mercado musical é composto por mulheres altamente escolarizadas se comparadas à média da população. $38,3 \%$ das respondentes têm curso superior completo e 18,7\% têm pós-graduação completa” (2019, p. 19) ${ }^{9}$

São também as mulheres que representam o maior percentual entre musicistas que têm vínculo de trabalho formal (Tabela 2). Os percentuais de renda per capita e de trabalho com vínculo formal são maiores nas pessoas com 50 anos ou mais e com maior grau de escolaridade em relação às mais jovens (Dados não apresentados em tabela). De acordo com Costa (2020), ao analisar os dados da Pesquisa Nacional por Amostra de Domicílios (PNAD) do ano de 2019,

A taxa de formalização global dos profissionais que concluíram o ensino superior é muito superior àquela referente aos que não alcançaram este nível escolar. As chances de um músico sem graduação universitária se inserir em algum tipo de formalização no mercado de trabalho é somente 38\% da de um músico com ensino superior (COSTA, 2020, p. 217).

Porém, segundo o autor, tal fato pode ser creditado "à tendência a engajamento de músicos com ensino superior em outras carreiras, com status de ocupação principal, correspondendo a música à sua fonte de renda complementar” (idem).

TABELA 2 - Características socioeconômicas e de trabalho segundo sexo. EPI-Música

\begin{tabular}{lccccc}
\hline Variáveis & \multicolumn{2}{c}{ Total } & Masculino & Feminino & $\mathrm{p}$ \\
\cline { 2 - 5 } & $\mathrm{n}$ & $\%$ & $\%$ & $\%$ & 0,504 \\
\hline Renda & & & & & \\
Até meio SM & 35 & 8,0 & 9,3 & 4,9 & \\
Meio a 1 SM & 57 & 13,1 & 13,5 & 12,5 & \\
1 a 2 SM & 127 & 29,1 & 29,4 & 29,2 & \\
2 a 4 SM & 137 & 31,4 & 30,5 & 32,6 & \\
4 ou mais & 80 & 18,4 & 17,3 & 20,8 & \\
Renda além da música & & & & & \\
Sim & 170 & 35,9 & 37,3 & 33,1 & \\
Não & 303 & 64,1 & 62,7 & 66,9 & \\
\hline
\end{tabular}

*Valores de p, resultados do teste de qui-quadrado. São estatisticamente significantes quando apresentam valores menores do que 0,05

\footnotetext{
${ }^{9}$ Núcleo de pesquisa e organização de dados e informações da Semana Internacional de Música - SIM São Paulo. Mulheres na Indústria da música no Brasil: Obstáculos, oportunidades e perspectivas. Data SIM, 2019. Disponível em: https://datasim.info/wp-content/uploads/2020/02/DATASIM_MULHERES_NA_MUSICA_2019.pdf Acesso em: janeiro de 2021.
} 
TABELA 2 (cont.) - Características socioeconômicas e de trabalho segundo sexo. EPI-Música

\begin{tabular}{|c|c|c|c|c|c|}
\hline \multirow[t]{2}{*}{ Variáveis } & \multicolumn{2}{|c|}{ Total } & \multirow{2}{*}{$\begin{array}{c}\text { Masculino } \\
\%\end{array}$} & \multirow{2}{*}{$\begin{array}{c}\text { Feminino } \\
\%\end{array}$} & \multirow[t]{2}{*}{$\mathrm{p}$} \\
\hline & $\mathrm{n}$ & $\%$ & & & \\
\hline Quanto a música representa no salário & & & & & 0,022 \\
\hline Menos de $80 \%$ & 165 & 35,0 & 38,5 & 27,9 & \\
\hline $80 \%$ ou mais & 307 & 65,0 & 61,5 & 72,2 & \\
\hline Provedor principal da renda no domicílio & & & & & 0,012 \\
\hline $\operatorname{Sim}$ & 307 & 64,9 & 68,8 & 57,1 & \\
\hline Não & 166 & 35,1 & 31,3 & 43,0 & \\
\hline Escolaridade & & & & & $<0,001$ \\
\hline Médio incompleto & 25 & 5,3 & 6,9 & 1,9 & \\
\hline Superior incompleto & 127 & 26,7 & 32,7 & 14,6 & \\
\hline Superior & 140 & 29,4 & 28,6 & 31,0 & \\
\hline Pós-graduação & 184 & 38,7 & 31,8 & 52,5 & \\
\hline Vínculo trabalhista & & & & & 0,007 \\
\hline Formal & 137 & 29,2 & 26,4 & 34,8 & \\
\hline Sem vínculo ou microempreendedor ou autônomo sazonal & 202 & 43,1 & 47,9 & 33,5 & \\
\hline Empresário ou autônomo fixo & 99 & 21,1 & 20,1 & 21,5 & \\
\hline Outros & 31 & 6,6 & 4,8 & 10,1 & \\
\hline Tem previdência & & & & & 0,599 \\
\hline Sim & 313 & 67,9 & 67,1 & 69,5 & \\
\hline Não & 148 & 32,1 & 32,9 & 30,5 & \\
\hline
\end{tabular}

*Valores de p, resultados do teste de qui-quadrado. São estatisticamente significantes quando apresentam valores menores do que 0,05

\subsection{Comparação entre os grupos - Interpretação da análise de regressão múltipla}

Após a apresentação das características sociais e demográficas dos musicistas amostrados, examinou-se o conjunto de fatores sociais associados à perda de renda. A análise dos dados (Tabelas 3 e 4) se baseia na observação dos valores de Razão de Chances ou Odds Ratio (OR), vinculados a cada variável, quantificando a chance do evento (perda da renda) acontecer segundo fatores demográficos e socioeconômicos. O OR expressa a magnitude da associação entre estas variáveis ${ }^{10}$.

\footnotetext{
${ }^{10} \mathrm{OR}=1$, associação nula, exposição não se relaciona com o evento; $\mathrm{OR}>1$ =associação direta, exposição positivamente relacionada com o evento, maior chance de o evento acontecer; $\mathrm{OR}<1=$ associação inversa, exposição negativamente relacionada com o evento, menor chance de o evento acontecer (GORDIS, 2017, p.222).
} 
TABELA 3 - Perda de renda com a música durante a pandemia segundo condições demográficas e socioeconômicas do musicista. EPI-Música

\begin{tabular}{|c|c|c|c|c|}
\hline Variáveis & $\begin{array}{c}\text { Perdeu renda } \\
\%\end{array}$ & $\mathrm{p}$ & OR (IC95\%) & OR ajustado* (IC95\%) \\
\hline Total & $68,2 \%$ & & & \\
\hline Sexo & & 0,001 & & \\
\hline Feminino & 58,1 & & 1 & 1 \\
\hline Masculino & 73,2 & & $1,97(1,31-2,96)$ & $1,68(1,06-2,67)$ \\
\hline Faixa etária & & 0,004 & & \\
\hline 18 a 39 & 74,3 & & 1 & 1 \\
\hline 40 a 49 & 68,6 & & $0,75(0,46-1,25)$ & $0,77(0,44-1,33)$ \\
\hline 50 ou mais & 56,7 & & $0,45(0,28-0,73)$ & $0,46(0,27-0,78)$ \\
\hline Cor da pele & & 0,008 & & \\
\hline Branca & 64,1 & & 1 & 1 \\
\hline Preta e parda & 76,7 & & $1,85(1,17-2,92)$ & $1,65(1,05-2,60)$ \\
\hline Regióes & & 0,666 & & \\
\hline Sul/Sudeste/Centro-Oeste & 67,6 & & 1 & - \\
\hline Norte/nordeste & 69,6 & & $1,10(0,71-1,70)$ & - \\
\hline Escolaridade & & 0,000 & & \\
\hline Superior incompleto & 83,2 & & 1 & 1 \\
\hline Superior & 69,9 & & $0,47(0,27-0,82)$ & $0,49(0,26-0,91)$ \\
\hline Pós-graduação & 54,4 & & $0,24(0,14-0,41)$ & $0,27(0,15-0,49)$ \\
\hline Renda prévia à pandemia & & 0,000 & & \\
\hline Menos do que $1 \mathrm{SM}$ & 74,2 & & 1 & - \\
\hline 1 a 2 & 74,8 & & $1,03(0,56-1,93)$ & - \\
\hline $2 \mathrm{a} 4$ & 68,4 & & $0,75(0,42-1,37)$ & - \\
\hline 4 ou mais SM & 46,8 & & $0,31(0,16-0,59)$ & - \\
\hline
\end{tabular}

*Ajustes por todas as variáveis da tabela. Nota: Os valores são estatisticamente significantes quando os intervalos de confiança (IC) não compreendem a associação nula (1) e encontram-se em negrito na tabela.

As associaçốes da perda de renda oriunda da música com sexo e com a cor/ raça declarada pelos indivíduos se apresentaram fortes. Embora representem cerca de um terço da amostra (32,7\%), são os musicistas autodeclarados pretos e pardos os mais propensos a perder rendimentos com música ao longo do isolamento social. Entre os brancos, $64,1 \%$ perderam renda, enquanto que entre os pretos e pardos, a perda foi de $76,7 \%$. $\mathrm{Na}$ análise ajustada foi possível observar uma probabilidade $65 \%$ maior de perda dos rendimentos nos negros em relação aos brancos. Esse cenário desfavorável pode ser mais bem compreendido se levarmos em consideração o fato de que as piores condiçôes de vida (objetivadas, em nosso estudo, pela baixa escolaridade e pelo vínculo empregatício não formal) estão colocadas, majoritariamente, para musicistas autodeclarados negros/as. Nesse sentido, o resultado apontado pela nossa pesquisa corrobora os estudos sobre os efeitos desiguais provocados pela pandemia para população branca e negra (demissóes, dificuldade de acesso à saúde, mortes, despejos, etc.) no Brasil. 
A probabilidade de perda de renda com a música foi $68 \%$ maior nos homens $(\mathrm{OR}=1,68) \mathrm{em}$ relação às mulheres, o que pode se justificar pelo maior percentual de mulheres situadas em trabalho formal, em relação à população masculina. Contudo, a possibilidade menor de perder renda durante o período de pandemia e isolamento social não implica, necessariamente, que as mulheres estejam vivenciando condições de trabalho mais favoráveis. Se antes a distribuição desigual das tarefas domésticas e do cuidado com a família se constituíam em vetores prejudiciais ao desenvolvimento de suas carreiras profissionais na área de música (SEGNINI, 2014, p. 82; PICHONERI, 2011, p. 4; REQUIÃO, 2020b, p. 258) podemos supor que essa situação tenha se agravado, levando as mulheres a exercerem jornadas duplas ou até triplas, sobrecarregando a saúde emocional, conforme sugerem estudos recentes (BARROS et al., 2020, p. 8; DATA SIM, 2019b, p. 29-30).

TABELA 4 - Perda de renda com a música durante a pandemia segundo características do rendimento e condiçôes de trabalho. EPI-Música

\begin{tabular}{|c|c|c|c|c|}
\hline Variáveis & $\begin{array}{c}\text { Perdeu } \\
\text { renda } \\
\%\end{array}$ & $\mathrm{p}$ & OR (IC95\%) & OR ajustado* (IC95\%) \\
\hline \multicolumn{5}{|l|}{ Rendimentos } \\
\hline Renda além da música & & 0,628 & & \\
\hline Não & 67,2 & & 1 & - \\
\hline Sim & 69,4 & & $1,11(0,74-1,66)$ & - \\
\hline $\begin{array}{l}\text { Quanto a música representa no } \\
\text { salário }\end{array}$ & & 0,032 & & \\
\hline Menos de $80 \%$ & 74,6 & & 1 & - \\
\hline $80 \%$ ou mais & 64,9 & & $0,63(0,41-0,96)$ & - \\
\hline $\begin{array}{l}\text { Provedor principal da renda no } \\
\text { domicílio }\end{array}$ & & 0,468 & & \\
\hline Não & 70,1 & & 1 & - \\
\hline Sim & 66,8 & & $0,86(0,57-1,29)$ & - \\
\hline \multicolumn{5}{|l|}{ Trabalho } \\
\hline Vínculo trabalhista & & 0,000 & & \\
\hline Formal & 36,6 & & 1 & 1 \\
\hline $\begin{array}{l}\text { Sem vínculo ou } \\
\text { microempreendedor ou autônomo } \\
\text { sazonal }\end{array}$ & 86,5 & & $11,12(5,71-21,6)$ & $7,60(3,60-16,01)$ \\
\hline Empresário ou autônomo fixo & 85,4 & & $10,6(6,16-18,14)$ & $8,14(4,38-16,0)$ \\
\hline Outros & 29,4 & & $0,72(0,32-1,63)$ & $0,35(0,11-1,02))$ \\
\hline
\end{tabular}

${ }^{*}$ Ajustes por sexo, faixa etária, cor da pele e escolaridade. Nota: Os valores são estatisticamente significantes quando os intervalos de confiança (IC) não compreendem a associação nula (1) e encontram-se em negrito na tabela. 
Pesquisa desenvolvida pelo Núcleo de Pesquisa e Organização de Dados e Informações sobre o Mercado Musical da Semana Internacional de Música - SIM São Paulo informa que, apesar da maioria das mulheres musicistas ser solteira e não ter filhos, entre aquelas que são mães, $80,6 \%$ têm filho com idade inferior a 18 anos (DATA SIM, 2019, p. 18). Estes dados podem ser conectados a resultados do nosso estudo, que indicam que musicistas do sexo masculino, em maior parte, são os provedores principais da renda do domicílio; a perda de renda relativamente maior de musicistas de sexo masculino pode assim prejudicar o sustento familiar, trazendo inseguranças, inclusive alimentar.

Por outro lado, a probabilidade dos musicistas com 50 anos de idade ou mais terem suas rendas atingidas foi $46 \%$ menor quando comparamos com a população mais jovem de nossa amostra. Situação semelhante pode ser observada para parcela de indivíduos que tinham, antes da pandemia, uma renda igual ou superior a quatro salários-mínimos $(\mathrm{OR}=0,31)$. A possibilidade de perder renda no período atual também foi $27 \%(\mathrm{OR}=0,27)$ menor entre aqueles que realizaram maior investimento escolar ao longo de suas carreiras. A questão da maior queda dos rendimentos entre os menos escolarizados pode se justificar pela informalidade no trabalho, que está fortemente relacionada ao nível de escolaridade. Nosso estudo detectou que, entre os músicos que não completaram o nível superior, apenas $10 \%$ têm vínculo formal de trabalho, enquanto o percentual é quatro vezes maior entre os pós-graduados.

Embora exista essa relação positiva entre anos de estudos e renda mais estável, vale considerar a especificidade da profissão do músico, categoria profissional cujo exercício não depende da aquisição de um diploma universitário (COSTA, 2020, p. 310). Ao contrário do que ocorre com outras áreas de saber e profissóes, a exemplo da medicina, advocacia, engenharia e psicologia, a prática profissional do músico e seu reconhecimento estão muito mais relacionados à mobilização de uma rede de contatos do que a qualificação formal/institucional na área. É, basicamente, através dessa rede de relações sociais que os músicos vão consolidando sua inserção no mundo do trabalho (cantando e/ou tocando em bares, bailes, casamentos, cerimoniais, casas de shows, como também, gravando, compondo e executando trilhas sonoras, jingles, por exemplo) e construindo suas 
carreiras e sua identidade profissional (TRAVASSOS, 1999, p. 124; MORATO, 2010, p. 6-7) ${ }^{11}$.

Contudo, é importante lembrar que o processo de reestruturação produtiva e acumulação flexível (REQUIÃO, 2010), em curso desde anos 1990, vêm afetando, e de forma significativa, o campo artístico musical no Brasil. Além do aumento do trabalho informal (trabalho por conta própria, "bicos”), a flexibilidade dos processos de trabalho no campo da música também é marcada pelo crescimento de subcontrataçôes, dos trabalhos temporários e rearranjos precários. O estudo sobre os músicos da Orquestra Sinfônica do Municipal de São Paulo (PICHONERI, 2011) e da Orquestra de Câmara Theatro São Pedro de Porto Alegre (BARTZ e OLIVEN, 2019) são exemplares sobre os efeitos provocados pela adoção de contratos temporários e jornadas flexíveis, nas condiçôes e relaçôes de trabalho entre os músicos. Não apenas a condição de assalariado do setor público temporário foi submetida à retirada de uma série de direitos trabalhistas (décimo terceiro, seguro saúde, licença maternidade, entre outros), como também a procura por outras atividades remuneradas, como estratégia para "aumentar a renda" e a "rede de contato", passou a ser comum entre os musicistas da orquestra (PICHONERI, 2011, p. 103-105; BARTZ e OLIVEN, 2019, p. 145-147). O aumento da procura por trabalho (e o surgimento da figura do trabalhador múltiplo assalariado), mas também o aumento do desemprego estrutural tem alterado a relação dos trabalhadores com o sistema escolar. Se, antes, o investimento escolar (e o prolongamento dos estudos), era percebido como meio de mobilidade social ascendente, hoje, conforme mostram pesquisas recentes, nacionais e internacionais, as estratégias de escolarização têm se constituído em estratégias de enfrentamento ao desemprego, à desclassificação social e à vulnerabilidade social (BAUDELOT, 2004, p. 24-25; POCHMANN, 2012, p. 145- 152; MAURIN, 2014, p. 23-24; PEROSA, LEBARON e LEITE, 2015, p. 111-112; DIEESE/2018, p. 1- 4). O diploma vem se constituindo num recurso de proteção contra situaçóes de precariedade social. Apontamentos semelhantes foram feitos, na área da música, por Mendes, Dutra e Pereira (2015) quando relacionaram o estudo formal e a média salarial dos músicos brasileiros. Os autores concluíram que o músico não graduado tem maiores "chances de aumentar sua renda mensal se investir na própria graduação" (p. 21), constatando que junto à rede de contatos, a aquisição do diploma propicia

\footnotetext{
${ }^{11} \mathrm{O}$ uso da rede de relações sociais na atuação da profissão em música não exclui, por outro lado, a precocidade da formação musical para determinados musicistas. O caso dos músicos de orquestra, analisado por Pichoneri (2006) e Travassos (1999) mostra que a formação acadêmica se constitui num recurso crucial tanto para musicistas, que só se percebem como músicos profissionais quando finalizada a formação universitária, quanto para seus pares.
} 
maiores chances de atuação no mercado de trabalho e de estabilidade financeira.

Ao analisarmos a perda de renda dos musicistas segundo características do rendimento e condições de trabalho, observamos que musicistas que têm menor chance de perda de renda durante a pandemia da Covid-19 são os trabalhadores com vínculo formal com a música (Tabela 4). Entre aqueles sem vínculo formal (microempreendedores, autônomos ou empresários) a chance de perda da renda é aproximadamente 8 vezes maior em relação aos trabalhadores com vínculo formal. Estas associações põem em evidência as vantagens da escolarização na inserção no mercado de trabalho formal e no aumento de chances para evitar situações de fragilidade e instabilidade socioeconômica. Ao mesmo tempo, nossos resultados corroboram os estudos sobre a correlação entre trabalho informal, empreendedorismo e precarização das condições de vida dos trabalhadores.

Com uma crescente tendência à terceirização de serviços, a indústria da música, assim como acontece nos demais setores produtivos, colabora com um intenso e crescente processo de precarização do trabalho por meio da contratação via CNPJ, mesmo quando o serviço é realizado por pessoa física. Esse processo é conhecido como “pejotização” quando pessoas físicas são levadas a aderirem ao Micro Empreendedorismo Individual (MEI) para poder emitir nota fiscal desonerando o empregador de qualquer obrigação trabalhista (REQUIÃO, 2017, p. 4 e 2020a, p. 19). De acordo com o relatório da DATA SIM (2020), na pandemia da COVID-19 “o prejuízo estimado das 'MEIs da Música ao Vivo' no país seria de 3 bilhôes de reais impactando cerca de 1 milhão de profissionais” (p. 17).

Por fim, nossa análise mostra que, apesar das disparidades existentes no que diz respeito à composição do mercado de trabalho nas regióes Sul e Sudeste e Norte e Nordeste do país, não houve diferença significativa na perda de renda entre musicistas das diferentes regióes. Todos foram atingidos no período de isolamento social provocado pela pandemia da Covid-19.

\section{Considerações Finais}

Ao considerar os resultados deste estudo é preciso levar em conta a limitação de que os sujeitos que não tinham acesso à internet foram excluídos da pesquisa. Essa exclusão tende a levar a um viés de informação e é possível que haja alguma subestimativa nos resultados encontrados. No 
entanto, no período estudado, diante das medidas de distanciamento social e do alto contágio da infecção em questão, o uso de questionários online se impóe para este tipo de pesquisa.

Muito esforço de pesquisa tem sido despendido para descrever e medir o impacto provocado pelo isolamento social em função da pandemia da Covid-19 nas diferentes categorias sociais. Nesse artigo, buscamos avançar uma proposta analítica com base num exame das características demográficas e socioeconômicas e a perda de renda de um conjunto de 476 musicistas de diferentes regiões do Brasil. A análise estatística das informações produzidas por meio da aplicação do questionário virtual revela que, independentemente da região de origem, a renda obtida com o trabalho no campo da música foi bastante reduzida para o conjunto de indivíduos de nossa amostra. Os resultados da análise apontam que a dimensão racial tem um efeito importante na perda de renda por parte dos musicistas, assim como a dimensão educacional (objetivado pelo grau de escolaridade dos músicos), a idade e as condiçóes de trabalho (tipo de vínculo) anterior ao processo de isolamento social.

Nesse sentido, nosso estudo permitiu traçar um perfil dos musicistas que tiveram sua renda atingida duramente, durante o período de isolamento social mais rígido. São os indivíduos autodeclarados negros (pardos e pretos) que mais perderam renda do trabalho com a música. Os homens e os mais jovens também foram os mais afetados quando comparados com as mulheres e com a população mais velha. As mulheres, embora tenham duplicado suas jornadas de trabalho durante o isolamento provocado pela pandemia, foram as que tiveram a renda menos prejudicada. Esta relação pode ser mais bem compreendida quando observamos a relação entre o grau de escolarização da população e as chances de perda de renda. Isto porque nosso estudo aponta que o nível de ensino influencia substancialmente e inversamente a perda de renda, uma vez que este fator se correlaciona fortemente ao tipo de vínculo empregatício dos indivíduos anteriormente a pandemia. Na medida em que o grau de instrução da população aumenta, maiores as chances de obter um vínculo formal no mundo do trabalho e, consequentemente, menores as chances de perder renda. O diploma acaba por funcionar como espécie de proteção social, sobretudo, se levarmos em consideração a precarização que vem sendo colocada nos últimos anos para o mercado das artes. No caso dos nossos entrevistados, observamos que são as mulheres que apresentam o maior nível de escolarização quando comparadas aos homens. Além disso, os indivíduos que 
tiveram a renda menos atingida são justamente aqueles que, antes da pandemia, desempenhavam uma atividade com vínculo formal.

Os resultados da pesquisa apontam para a necessidade de cuidados e estratégias que contribuam para reduzir os prejuízos das ondas da Covid-19 nas condiçốes de vida da população, em especial da categoria de musicistas. Contudo, vale observar que as formas como musicistas se mantêm ativos no mercado de trabalho, adaptando-se a cada nova "onda" - principalmente por conta do impacto da tecnologia como o principal meio de produção (vide a chamada Era do Acesso) $)^{12}$ - aquilo que hoje prega-se como um processo de reinvenção há tempos já é uma condição imposta à classe que vive da cultura. Não à toa, o relatório da FIRJAN do ano de 2019, ao analisar a Indústria Criativa no Brasil, nos impunha a necessidade de nos "reinventarmos" e de "sairmos da caixa” (p. 9), por conta de novos modelos de negócios em curso. Assim, entendemos que a pandemia não só acelerou processos que já vinham acontecendo - de precarização das relaçóes de trabalho e do incremento da tecnologia como meio fundamental na gestão e nos modelos de negócios, por exemplo - como expôs a vulnerabilidade à qual trabalhadores e trabalhadoras da música vêm sendo submetidos. Em função de tecnologias que permitem o acesso ao conteúdo musical - como as plataformas de streaming - a indústria da música vem se reconfigurando e transformado formas de produção e consumo. Como consequência, conforme aponta De Marchi, "o nível de concentração financeira entre as majors seria algo sem paralelos na história da indústria” (2020, p. 239). Nesse sentido, acenamos para a necessidade de políticas públicas que assegurem o emprego, o desenvolvimento de arranjos culturais locais/regionais de artistas "independentes", e toda a forma de manifestação artística, a fim de garantir a tão apregoada diversidade cultural.

\section{REFERÊNCIAS}

BARBOSA, Jerônimo Rogério, PRATES, Ian. Efeitos do desemprego, do auxílio emergencial e do Programa Emergencial de Preservação do Emprego e da Renda (MP 936) sobre a renda, a pobreza e a desigualdade durante e depois da pandemia. MERCADO DE TRABALHO, v. 69, p. 65, 2020. Disponível em: $<$ http://repositorio.ipea.gov.br/bitstream/11058/10187/1/bmt 69 EfeitoDesemprego.pdf $>$. Acesso em 22 de setembro de 2020.

\footnotetext{
${ }^{12}$ Sobre a Era do Acesso ver Rifkin (2001)
} 
BARROS, Marilisa Berti de Azevedo et al. Report on sadness/depression, nervousness/anxiety and sleep problems in the Brazilian adult population during the COVID-19 pandemic. Epidemiol. Serv. Saúde, Brasília, v. 29, n. 4, e2020427, 2020. Disponível em: <https://doi.org/10.1590/s167949742020000400018>. Acesso em: 22 de setembro de 2020.

BARTZ, Guilherme Furtado; OLIVEN, Ruben George. Como o trabalho flexível afeta os músicos eruditos? O caso da orquestra de câmara Theatro São Pedro de Porto Alegre. Sociol. Antropol., Rio de Janeiro, v. 9, n. 1, p. 135-158, Apr. 2019. Disponível em: https://doi.org/10.1590/2238$\underline{38752019 \mathrm{v} 916}$

BAUDELOT, C. As qualificações aumentam, mas a desigualdade torna-se ainda maior. ProPosiçôes, Campinas, SP, v. 15, n. 2, p. 15-38, 2004. Disponível em: $<$ https://periodicos.sbu.unicamp.br/ojs/index.php/proposic/article/view/8643807>. Acesso em: 19 mar. 2021.

COSTA, Rodrigo Heringer. A música como arte de viver em Salvador. Tese (Doutorado em Música). UFBA, Bahia, 2020.

DATA SIM. COVID-19: impacto no mercado da música do Brasil. Núcleo de pesquisa e organização de dados e informaçôes sobre o mercado musical da Semana Internacional de Música SIM São Paulo, 2020. Disponível em: <https://datasim.info/pesquisas/>. Acesso em: 19 de novembro 2020.

DATA SIM. Mulheres na indústria da música no Brasil: obstáculos, oportunidades e perspectivas. Núcleo de pesquisa e organização de dados e informaçôes sobre o mercado musical da Semana Internacional de Música - SIM São Paulo, 2019. Disponível em: $<$ https://datasim.info/pesquisas/>. Acesso em: 19 de novembro 2020.

DE MARCHI, Leonardo. Pós-streaming: um panorama da indústria fonográfica na Quarta Revolução Industrial. MAGI, Érica (ed.); DE MARCHI, Leonardo (ed.). Diálogos Interdisciplinares sobre a Música Brasileira. Faculdade de Filosofia e Ciências - FFC - Campus de Marília, p. 223-248, 2020. Disponível em: < https://ebooks.marilia.unesp.br/index.php/lab editorial/catalog/book/176>. Acesso em: $17 \mathrm{de}$ março 2021.

DIESSE/2018. Boletim Emprego em Pauta, DIEESE, agosto de 2018. Disponível em < https://www.dieese.org.br/boletimempregoempauta/2018/boletimEmpregoEmPauta9.pdf $>$.

Acesso em: 15 de março 021

DIEESE/2018, Boletim Emprego em Pauta. Disponível em: <https://www.dieese.org.br/boletimempregoempauta/2018/boletimEmpregoEmPauta9.pdf $>$.

Acesso em: 19 de março 2021.FIRJAN. Mapeamento da indústria criativa no Brasil. 2019. Disponível em: <http://www.firjan.com.br>. Acesso em: 12 de maio 2019.

GORDIS, Leon. Epidemiologia. 5. ed. Rio de Janeiro: Thieme Revinter Publicações, 2017.

HASENBALG, Carlos (Org.); VALLE SILVA, Nelson do (Org.). Origens e DestinosDesigualdades Sociais ao Longo da Vida. 1. ed. Rio de Janeiro: TopBooks, 2003. v. 01. 480p

INEP/2015. Censo da educação superior 2013: resumo técnico. Brasília: Instituto Nacional de Estudos e Pesquisas Educacionais Anísio Teixeira, 2015. Disponível em: 
$<$ http://portal.inep.gov.br/documents/186968/484154/Resumo+T\%C3\%A9cnico+Censo+da+E duca\%C3\%A7\%C3\%A3o+Superior+2015/dd2d280c-f644-4776-95ae-

28029c928e20?version=1.0 >. Acesso: em 18 de março 2021

MAURIN, Eric. La mobilité sociale des nouvelles classes moyennes. In: Idées économiques et sociales, no 175, 2014. Disponível em: <https://www.cairn.info/revue-idees-economiques-etsociales-2014-1-page-25.htm>. Acesso: em 18 de março 2021.

MENDES, Kassio; DUTRA, Lívia Maria; PEREIRA, Denise Perdigão. Relação entre o estudo formal e a média salarial do músico... Per Musi. Belo Horizonte, n.32, p. 296-322, 2015. DOI: 10.1590/permusi2015b3211

MENGER, Pierre-Michel. Retrato do artista enquanto trabalhador: metamorfoses do capitalismo. Lisboa: Roma Editora, 2005.

MORATO, Cíntia Thais. A formação profissional em música: uma reflexão pensada sob o ponto de vista da construção social da profissão musical. In: XVIII CONGRESSO NACIONAL DA ABEM. Anais, Goiânia-GO, 28 de julho a 01 de outubro de 2010, p. 220-230. Disponível em $<$ https://www.academia.edu/39009594/A forma\%C3\%A7\%C3\%A3o profissional em m\%C3\% BAsica uma reflex\%C $3 \% \mathrm{~A} 30$ pensada sob o ponto de vista da constru\%C $3 \% \mathrm{~A} 7 \% \mathrm{C} 3 \% \mathrm{~A} 3 \mathrm{o}$ social da_profiss\%C3\%A3o_musical >. Acesso: em 18 de março 2021.

OLINTO, Gilda. A inclusão das mulheres nas carreiras de ciência e tecnologia no Brasil. Inclusão Social, Brasília, v. 5, n. 1, p. 68-77, jul./dez. 2012. Disponível em < http://revista.ibict.br/inclusao/article/view/1667>. Acesso: em 18 de março 2021.

PEROSA, Graziela S.; LEBARON, Fredéric; LEITE, Carla. K. S. . O espaço das desigualdades educativas no município de São Paulo. PRÓ-POSIÇÕES (UNICAMP. ONLINE), v. 26, p. 99118, 2015. Disponível em: <https://www.scielo.br/pdf/pp/v26n2/0103-7307-pp-26-020099.pdf>. Acesso: em 18 de março 2021.

PEUGNY, Camille. Le destin au Berceau. Inégalités et reproduction sociale. Paris: Seuil, 2014.

PICHONERI, Dilma Fabri Marão. Músicos de orquestra: Um estudo sobre educação e trabalho no campo das artes. Dissertação (Mestrado em Educação). UNICAMP, Campinas, SP. 2006. Disponível em: <http://repositorio.unicamp.br/jspui/handle/REPOSIP/252725>. Acesso: em 18 de março 2021.

Relaçôes de trabalbo em música: a desestabilização da harmonia. Tese (Doutorado em Educação), UNICAMP. Campinas, SP. 2011. Disponível em: < http://repositorio.unicamp.br/jspui/handle/REPOSIP/251147> . Acesso: em 18 de março 2021.

POCHMANN, Marcio Pochmann, M. (2012). Trabalho e Formação. Educação e Realidade, 37, 337-708. Disponível em: <https://seer.ufrgs.br/educacaoerealidade/article/view/30490>. Acesso em: 18 de março 2021.

REQUIÃO, Luciana. "Eis aí a Lapa...”: processos e relaçôes de trabalho do músico nas casas de shows da Lapa. São Paulo: Annablume, 2010.

"Festa acabada, músicos a pé!": um estudo crítico sobre as relações de trabalho de músicos atuantes no estado do Rio de Janeiro. Revista do Instituto de Estudos Brasileiros, n. 64, p. 249-274, 
São Paulo. Disponível em: <https://doi.org/10.11606/issn.2316-901X.v0i64p249-2744>. 2016.

. A morte (ou quase morte) do músico como um trabalhador autônomo. In: COLÓQUIO INTERNACIONAL MARX E O MARXISMO 2017: De O capital à Revolução de Outubro (1867-1917), 2017, Niterói. Anais. Disponível em:

$<$ https://www.researchgate.net/profile/Luciana Requiao/publication/337153832 A morte ou quase morte do musico como um trabalhador autonomo e a ode ao empreendedorismo/li nks/5dc814bf4585151435fd62e0/A-morte-ou-quase-morte-do-musico-como-umtrabalhadorautonom >. Acesso em: 8 de maio 2020.

- Trabalho, Música e Gênero: depoimentos de mulheres musicistas acerca de sua vida laboral. Um retrato do trabalho no Rio de Janeiro dos anos 1980 ao início do século XXI. Rio de Janeiro: Edição da autora, 2019. Disponível em: $<$ https://issuu.com/lucianareq/docs/livro_trabalho_musica_genero_fechado $>$. Acesso em: 9 de outubro de 2019.

- Mundo do trabalho e música no capitalismo tardio: entre o reinventar-se e o sair da caixa. Opus, v. 26 n. 2, p. 1-25, maio/ago. 2020a.

Mulheres musicistas e suas narrativas sobre o trabalho: um retrato do trabalho no Rio de Janeiro na virada do século XX ao XXI. Revista ECO, v. 23, n. 1, p. 239-165, 2020 b.

RIBEIRO, C. A. C. Desigualdade de oportunidades e resultados educacionais no Brasil. DADOS, Revista de Ciências Sociais, Rio de Janeiro, 54(1), 41-87, 2011. Disponível em: $<$ https://doi.org/10.1590/S0011-52582011000100002>

RIFKIN, Jeremy. A era do acesso: a transição de mercados convencionais para networks e o nascimento de uma nova economia. São Paulo: MAKRON Books, 2001.

SEGNINI, Liliana Rolfsen Petrilli. Os músicos e seu trabalho: diferenças de gênero e raça. Tempo Social, revista de sociologia da USP, vol. 26, n.1, p. 75-86. Disponível em: $<$ https://doi.org/10.1590/S0103-20702014000100006>. 2014.

. O que permanece quando tudo muda? Precariedade e vulnerabilidade do trabalho na perspectiva sociológica. Caderno CRH [online], vol. 24, n. spe 1, p. 71-88. Disponível em: $<$ https://doi.org/10.1590/S0103-49792011000400006>. 2011.

- Educação e Trabalho: uma relação tão necessária quanto insuficiente. São Paulo em Perspectiva, 14, 72-81. Disponível em: <https://doi.org/10.1590/S0102-88392000000200011>, 2000

SIMÕES, Julia da Rosa. Ser músico e viver de música no Brasil: um estudo da trajetória do Centro Musical Porto-Alegrense (1920-1933). Dissertação (Mestrado em História). PUCRS, Porto Alegre, 2011. Disponível em: <http://tede2.pucrs.br/tede2/handle/tede/2386>. Acesso em: 17 de março 2021.

TRAVASSOS, Elizabeth. Redesenhando as fronteiras do gosto: estudantes de música e diversidade musical. Horiz. antropol., Porto Alegre, v. 5, n. 11, p. 119-144, Oct. 1999. Disponível em: http://dx.doi.org/10.1590/S0104-71831999000200006

SOUZA, Sanda Duarte. Educação, trabalho e socialização de gênero: quando ser mulher pesa mais 
na balança da desigualdade social. Educação E̊ Linguagem, v. 18, p. 170-185, 2008. Disponível em:

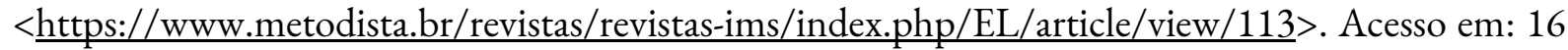
de março 2021.

VARGAS, H. M. (2009). (I)mobilidade social pela via do ensino superior. Rio de Janeiro: Anais do Congresso Brasileiro de Sociologia.

\section{SOBRE OS AUTORES}

Clara Sandroni é professora de Canto Popular na Universidade Federal de Minas Gerais - UFMG. Possui Graduação em Música pela Universidade Federal do Estado do Rio de Janeiro - UNIRIO (2004), Mestrado em Música pela Universidade Federal Rio de Janeiro - UFRJ (2013), e Doutorado em Música na UNIRIO (2017). Tem experiência na área de Artes, com ênfase em Música, atuando principalmente nos seguintes temas: música popular brasileira, canto popular e técnica de canto popular. ORCID: https://orcid.org/0000-0002-4276-5226. E-mail: clarasandroni19@gmail.com

Carlos Sandroni é professor de Etnomusicologia no Departamento de Música da UFPE (Recife). Tem Mestrado em Ciência Política (IUPERJ, 1987) e Doutorado em Musicologia (Universidade de Tours, França, 1997). Foi professor visitante nas universidades do Texas em Austin (2007), e de Indiana em Bloomington (2015). Foi presidente da Associação Brasileira de Etnomusicologia (2002-2004). Publicou os livros "Mário contra Macunaíma: cultura e política em Mário de Andrade", e "Feitiço decente: transformaçôes do samba no Rio de Janeiro, 1917-1933". ORCID: https://orcid.org/0000.0003.4828.5765. E-mail: carlos.sandroni@gmail.com

Daniela Maria Ferreira é professora do Centro de Educação e do Programa de Pós- Graduação em Música da UFPE. Tem experiência na área de Sociologia, com ênfase em Sociologia da Educação e Sociologia da Cultura.

ORCID: https://orcid.org/0000-0002-2871-1141. E-mail: dmffr@yahoo.fr

Luciana Pires de Sá Requião é musicista, professora e pesquisadora. Integra a Orquestra Lunar e a coletiva Primavera das Mulheres. É professora da Universidade Federal Fluminense e vem atuando junto ao Programa de Pós-Graduação em Música e ao Programa de Mestrado Profissional em Ensino das Práticas Musicais, ambos da UNIRIO, e ao Programa de Pós-Graduação em Cultura e Territorialidades da UFF. Coordena o Grupo de Estudos em Cultura, Trabalho e Educação e está como diretora do Sindicato dos Músicos do Estado do Rio de Janeiro na gestão 2019-2022. ORCID: https://orcid.org/0000-0003-0351-0578. E-mail: lucianarequiao@id.uff.br 
SANDRONI, Clara; FERREIRA, Daniela Maria; REQUIÃO, Luciana Pires de Sá; SANDRONI, Carlos; LIMA, Margareth Guimarães. A Covid19 e seus efeitos na renda dos músicos brasileiros. Revista Vórtex, Curitiba, v.9, n.1, p. 1-23, 2021.

Margareth Guimarães Lima possui doutorado em Saúde Coletiva pela Universidade Estadual de Campinas (UNICAMP), área de concentração epidemiologia. Atualmente é pesquisadora na Faculdade de Ciências Médicas da UNICAMP, com atuação no Centro Colaborador em Análise de Situação de Saúde (CCAS). Atua em linhas de pesquisa das doenças crônicas não transmissíveis, sobretudo com Inquéritos de Saúde de Base Populacional. Docente permanente do programa de pós-graduação em Saúde Coletiva (PPGSC), da UNICAMP e membro da Comissão de Pós-graduação deste programa. ORCID: https://orcid.org/0000-0001-9402-3139. E-mail: margarethglima@gmail.com 